representative and not biased towards the outcomes of particular centres. The production of such graphs in two stages allows for the changing pattern of survival from the start of the intrapartum period to the immediate period after admission for neonatal care. A continual process of updating needs to be in place to allow for improvements in survival of infants.

We thank Sue Wood (regional coordinator), Jayne Bennett (administrator), and all the district coordinators for the Trent confidential inquiry into stillbirths and deaths in infancy, the staff (medical, nursing, and clerical) of the 16 perinatal units in Trent, those units adjacent to Trent that allowed us access to data on cross boundary flows of patients, and Keith Abrams and Nicky Spiers for their statistical advice.

Contributors: DJ, ESD, and DJF conceived the original idea for the study; they will act as guarantors for the paper. All authors contributed to the writing of the paper. BM carried out the statistical analysis.

Funding: The Trent neonatal survey and Trent confidential inquiry into stillbirths and deaths in infancy are funded through the Trent regional office

Competing interests: None declared.

1 Field DJ, Hodges S, Mason E, Burton P, Yates J, Wale S. The demand for neonatal intensive care. $B M J$ 1989;299:1305-8.

2 Copper RL, Goldenberg RL, Creasy RK, DuBard MB, Davis RO, Entman $\mathrm{SS}$, et al. A multicenter study of preterm birth weight and gestational agespecific neonatal mortality. Am J Obstet Gynecol 1993;168:78-84

3 Verloove-Vanhorick SP, Verwey RA, Brand R, Gravenhorst JB, Keirse
MJNC, Ruys JH. Neonatal mortality risk in relation to gestational age and birthweight. Lancet 1986;1:55-7

4 Clarke M, Draper ES, James D, McKeever P, Perkins MJ, Wood S. Confidential enquiry into stillbirths and deaths in infancy (CESDI) 1994-5-one of the Trent infant mortality and morbidity studies. Leicester: Trent Institute for Health Services Research; 1996.

5 Burton P, Draper ES, Fenton A, Field DJ. Neonatal intensive care cots: estimating the population-based requirement in Trent UK. $J$ Epidemiol Community Health 1995; 48:617-28,

6 Greenberg DN, Yoder BA, Clark RH, Butzin CA, Null DM. Effect of maternal race on outcome of preterm infants in the military. Pediatric. 1993;91:572-7.

7 Yuksel B, Greenough A. Ethnic origin and lung function in infants born prematurely. Thorax 1995;50:773-6.

8 Fuentes-Afflick E, Hessol NA. Impact of Asian ethnicity and national origin on infant birthweight. Am J Epidemiol 1997;145:148-55.

9 Hosmer DW, Lemeshow S. Goodness of fit tests for the multiple logistic regression model. Commun Statist Theor Methods 1980;A9:1043-69.

10 Rennie JM. Perinatal management at the lower margin of viability. Arch Dis Child 1996;74:214-8F

11 Field D, Milner AD, Hopkin IE, Madeley RJ. Changing overall workload in neonatal units. $B M J 1985 ; 290: 1539-42$

12 Field D, Milner AD, Hopkin IE, Madeley RJ. The changing pattern of neonatal respiratory disease. Pediatr Pulmomol 1987;8:231-5.

13 Wolf EJ, Vintzileos AM, Rosenkranz TS, Rodis JF, Lettieri L, Mallozzi A. A comparison of pre-discharge survival and morbidity in singleton and twin very low birth weight infants. Obsterics Gynecol 1992;80:436-9.

14 Cooper TR, Berseth CL, Adams JM, Weisman LE. Acturial survival in the premature infant less than 30 weeks' gestation. Pediatrics 1998;101:975-8.

15 Tin W, Wariyar U, Hey E for the northern neonatal network. Changing prognosis for babies of less than 28 weeks' gestation in the north of England between 1983 and 1994. BMJ 1997;314:107-11.

16 Cartlidge PH, Stewart JH. Survival of very low birthweight and very preterm infants in a geographically defined population. Acta Paediat 1997;86:105-10.

(Accepted 13 July 1999)

\title{
Two view mammography at incident screens: cost effectiveness analysis of policy options
}

Katharine Johnston, Jackie Brown

\begin{abstract}
Objective To determine the cost effectiveness of two view mammography at incident screens.

Design Incremental cost effectiveness analyses recognising differences in current reading policy, based on effectiveness data from an observational study.

Setting Breast screening programmes in England and Wales.

Main outcome measures Health service costs, cancers detected, incremental cost effectiveness ratios per cancer detected, whole time equivalent staff. Results For programmes currently using one view with some form of double reading, the incremental cost effectiveness ratio of two view mammography at incident screens ranged between $£ 6589$ and $£ 6716$, depending on the reading policy. For programmes currently using one view with single reading, two policy options were found to be more efficient than two view single reading: one view with double reading (arbitration; incremental cost effectiveness ratio of $£ 210$ ) and two view double reading (arbitration). If programmes using one view with single reading changed to double reading (arbitration) and then subsequently to two views double reading (arbitration), additional cancers could be detected with an incremental cost effectiveness ratio of $£ 7983$. The implementation cost of two view mammography at
\end{abstract}

incident screens in programmes in England and Wales would be £2.9 million and would require 13.4 whole time equivalent radiologists.

Conclusions The cost effectiveness of two view mammography at incident screens depends on the film reading policy. A policy of two view mammography at incident screens in England and Wales would be efficient only if programmes using single reading moved to double reading. Given limited resources, priority should be given to introducing double reading in the subset of programmes currently using single reading as this requires fewer additional radiologists and is more cost effective.

\section{Introduction}

The NHS breast screening programme was introduced in 1987 after the recommendations of the Forrest report. ${ }^{1}$ The recommended policy was to invite women between the ages of 50 and 64 years for mammographic screening every three years with one view mammography. The report concluded that the age range, frequency of screening, and screening methods should be kept under review. It was also recommended that an economic component should be built into studies of these policy options as the costs and benefits of screening would be affected.
Health Economics Research Centre, University of Oxford, Institute of Health Sciences, Headington, Oxford OX3 7LF

Katharine Johnston research fellow

Health Economics Research Group, Brunel University, Uxbridge,

Middlesex

UB8 3PH

Jackie Brown

senior research fellow

Correspondence to: K Johnston kathy.johnston@his. ox.ac.uk

BMJ 1999;319:1097-102 
Research is currently under way to examine the effectiveness and cost effectiveness of various policy options at a national level. In such analyses it is important to recognise that each individual programme maintains some discretion as to the way in which their service is organised and delivered locally. This currently includes the use of single or double reading of films.

Two view mammography at the prevalent (initial) screen was adopted as national policy in $1995^{2}$ after evidence on effectiveness and cost effectiveness. ${ }^{3}$ At incident (subsequent) screens women generally receive single view mammography. The distinction between these two types of screen is important as the expectation is that the cancer detection rate will decline in incidence screening rounds (see box). Recently, with the realisation of higher than expected interval cancer rates in the NHS breast screening programme, there has been much discussion about whether two view mammography should be introduced nationally at incident screens.

Two view mammography at incident screens is likely to increase the screening costs but may result in savings in assessment costs if the recall rate falls. The current use of double reading by some screening programmes has cost implications for implementing two view mammography as the second view would have to be read twice. In addition, it cannot be assumed that the effect of two views will be the same where double reading is currently used compared with where single reading is being used. ${ }^{4}$ There are several methods of double reading, and this results in various policy options. An efficient policy option is one where the additional cost per unit of additional effect is considered good value for money relative to other options. Even if a policy option is judged efficient, the decision to implement the policy may be constrained by available resources. For example, the current shortage of radiological staff in the NHS breast screening

\section{Terminology}

Prevalent screen: A woman's first screen; two view mammography is mandatory policy

Incident screen: Subsequent screens; currently no mandatory policy on number of views for these screens

Double reading (recall if one reader suggests): Two radiologists read films independently, and a woman is recalled if at least one reader suggests

Double reading (consensus): Two radiologists read films independently. Disagreement is settled by consensus discussion between two readers

Double reading (arbitration): Two radiologists read films independently, and when there is disagreement a third radiologist decides whether a woman should be recalled

Inefficient policy options: If policy options are ordered in terms of increasing effectiveness, inefficient options can be identified. An inefficient policy option is one which has:

- Higher costs and lower effects than an alternative option or

- A higher cost effectiveness ratio than a more effective alternative option
Table 1 Reading policies operated by screening programmes and numbers screened

\begin{tabular}{lcc} 
Policy on incident round & $\begin{array}{c}\text { No of } \\
\text { programmes }\end{array}$ & $\begin{array}{c}\text { Total No of women } \\
\text { screened with policy } \\
\text { (1996-7) }\end{array}$ \\
\hline One view single reading & 17 & 133902 \\
\hline $\begin{array}{l}\text { One view double reading (recall if one } \\
\text { reader suggests) }\end{array}$ & 23 & 194502 \\
\hline One view double reading (consensus) & 14 & 110755 \\
\hline One view double reading (arbitration) & 6 & 64520 \\
\hline One view double reading (complex) & 23 & 211483
\end{tabular}

programme may mean that some policy options are not feasible.

We estimated the cost effectiveness of introducing two view mammography at incident screens compared with one view mammography. In doing so we examined the effect of reading policy on the cost effectiveness of two view mammography and estimated the implementation costs of the alternative policy options.

\section{Methods}

We estimated the cost effectiveness of two view mammography at incident screens for the 43 programmes currently using one view with double reading. Of the 43 programmes, 23 use double reading with recall for further assessment if either reader suggests or recommends recall; 14 programmes use double reading with consensus (where disagreement of a decision to recall for further assessment is settled by consensus discussion between the two readers); six programmes use double reading with arbitration (where disagreement about recall for further assessment is settled by arbitration by a third, or more, radiologist). A further 23 programmes use complex double reading, which has components of single, double, and triple reading. Programmes using complex double reading were excluded from the main analysis as there were too many combinations to be informative and no separate estimates of their effectiveness. ${ }^{4}$ We assumed that programmes currently using double reading would maintain the same reading policy with two views.

The cost effectiveness of two view mammography at incident screens or double reading, or both, was also estimated for the 17 programmes currently using one view with single reading. The number of programmes operating the different reading policies is summarised in table 1 . Four programmes currently use two views at incident screen $^{4}$ and these were excluded from the analysis.

The perspective of the cost analysis was the health service. The unit cost of one view single reading was taken from Johnston et al. ${ }^{5}$ The unit cost of one view double reading was estimated by using data previously collected from eight breast screening programmes. ${ }^{5}$ The costs included staff time (taking, processing, and reading of films and administering results), consumable items (films and chemicals), overheads (such as heating and lighting), and capital (buildings and equipment). A single reading and report on two films (one view) by a radiologist was assumed to be 0.68 minutes (based on a rate of 1980 images read in 678 minutes). ${ }^{6}$ The reading and reporting of a film by all forms of 
double reading was assumed to take twice as long as single reading. In addition, for double reading with consensus or arbitration, the proportion requiring consensus or arbitration was assumed to be $9.94 \%{ }^{7}$ Consensus was assumed to require the equivalent of an additional reading and report by each of the radiologists. Arbitration was assumed to require the equivalent of an additional reading and report by a third radiologist.

The additional time associated with a two view screen for screen taking and processing by a radiographer was assumed to be four minutes. ${ }^{8}$ The additional reading and reporting time by a radiologist for a single reading of the second views was assumed to be 0.68 minutes (as above $)^{6}$ and twice this amount for double reading. The proportion requiring consensus or arbitration was assumed to be unaltered.

The cost of a single assessment visit was taken from Johnston et $\mathrm{al}^{5}$ and increased by the proportion of women having further assessment visits ( $5 \%$ of women screened were estimated to have a further assessment visit). ${ }^{5}$ All costs were uprated to $1996-7$ prices by using the hospital and community pay and prices index.

Effectiveness was measured in terms of the additional cancers detected. The increase in small invasive cancers $(<15 \mathrm{~mm})$ detected per 10000 women screened was estimated from the figures presented by Blanks et al, ${ }^{4}$ based on the standardised detection ratio method. ${ }^{9}$ The increase in large invasive cancers $(>15 \mathrm{~mm})$ was not found to be significant. The cancer detection rates are based on an observational study rather than a randomised controlled trial as no trial data are available.

\section{Cost effectiveness ratios}

For the 43 programmes that use one view mammography with some form of double reading incremental cost effectiveness ratios were estimated by dividing the additional cost (per 10000 women screened) of two view mammography by the additional cancers detected compared with the initial baseline.

For the 17 programmes currently using one view mammography and single reading, incremental cost effectiveness ratios were estimated for the alternative policy options compared with current practice, and policy options were ordered in terms of increasing effectiveness. ${ }^{10}$ Policy options that produce greater costs and lower effects than others are inefficient. These options were excluded from further consideration, and incremental cost effectiveness ratios were then recalculated for the remaining options, as the ratio of the difference in costs to the difference in effects compared with the next (more effective) policy. A policy option is also inefficient if its cost effectiveness ratio is greater than the next (more effective) policy option as additional effectiveness is produced at a higher additional cost than necessary. ${ }^{10}$ These options were excluded from further consideration and the incremental cost effectiveness ratios were recalculated. The remaining policy options were then deemed efficient.

\section{Sensitivity analysis}

Uncertainty in the cost estimates was examined by performing several one way sensitivity analyses. ${ }^{11}$ Robustness was defined as no change in the ordering of the efficient policy options. By using an alternative figure from the literature, the number of minutes required to take and process the second view was reduced from four minutes ${ }^{8}$ to one minute 54 seconds (based on 251 timings of radiographers screening by one and two views). ${ }^{3}$ The proportion of films requiring consensus or arbitration was reduced from $9.94 \%$ to $6.45 \%,{ }^{7}$ and the cost of arbitration was assumed to be equivalent to an extra three radiologists reading and reporting.

The baseline analysis assumed that a change in policy did not affect the recall rates for further assessment. In the sensitivity analysis it was assumed that the baseline recall rate for one view single reading fell by $15 \%$ with two views. ${ }^{3}$ The baseline recall rate of $3.6 \%$ for one view single reading was taken from the KC62 annual returns (1996-7). The recall rates for all other policies were assumed not to change. A second sensitivity analysis on recall rates assumed that recall rates for all two view options fell by $15 \%$ compared with one view. ${ }^{3}$ The following recall rates were used for one view double reading the double reading policies: $3.4 \%$ double reading (recall if one reader suggests); $3.1 \%$ for double reading (consensus); and $4.0 \%$ for double reading (arbitration). ${ }^{4}$

Uncertainty in effectiveness was examined by performing a sensitivity analysis in which the number of cancers detected was varied by using the $95 \%$ confidence intervals around the number of cancers detected as the lower and upper values. ${ }^{4}$

\section{Total costs and whole time equivalent staff}

The total cost of implementing the policy options was estimated on the basis of the number of women screened in each of the programmes by using the different baseline reading policies from KC62 data 1996-7. The numbers screened are shown in table 1 . The number of whole time equivalent radiologists and radiographers required to implement each policy was estimated by multiplying the number of women screened with each policy (from KC62 data for 1996-7) by the additional minutes of radiology and radiography time required per woman. As staff can be employed on a sessional basis (3.5 hours) the additional time needed was rounded up to the nearest number of sessions. For policies moving from single reading to double reading (arbitration), the additional number of radiologists required was multiplied by two as two additional radiologists would have to be employed.

\section{Results}

The unit costs of a screen for each of the different policies varied between $£ 9.24$ (one view single reading) to $£ 15.21$ (two view double reading (consensus)). The average cost of assessment was $£ 47.18$.

Table 2 presents the additional costs, additional cancers detected, and incremental cost effectiveness ratios for the 43 programmes using one view with some form of double reading. The incremental cost effectiveness ratio of two view mammography ranges between $£ 6589$ and $£ 6716$, depending on the initial reading policy.

Table 3 presents the additional costs, additional cancers detected, and incremental cost effectiveness 
Table 2 Incremental cost effectiveness ratios from baseline of one view with some form of double reading*

\begin{tabular}{|c|c|c|c|}
\hline Policy & $\begin{array}{l}\text { Additional costs } \\
\qquad(£) \dagger\end{array}$ & $\begin{array}{l}\text { Additional cancers } \\
\text { detected†‡ ( } 95 \% \mathrm{Cl})\end{array}$ & $\begin{array}{l}\text { Incremental cost effectiveness } \\
\text { ratio }(95 \% \mathrm{Cl})\end{array}$ \\
\hline $\begin{array}{l}\text { Baseline: one view, double reading (recall if one reader suggests) to two } \\
\text { views, double reading (recall if one reader suggests) }\end{array}$ & 39538 & $6(3$ to 8$)$ & 6589 (13 179 to 4942$)$ \\
\hline $\begin{array}{l}\text { Baseline: one view, double reading (consensus) to two views, double } \\
\text { reading (consensus) }\end{array}$ & 40296 & $6(3$ to 10$)$ & 6716 (13 432 to 4030$)$ \\
\hline $\begin{array}{l}\text { Baseline: one view, double reading (arbitration) to two views, double } \\
\text { reading (arbitration) }\end{array}$ & 39917 & 6 (3 to 10) & 6652 (13 306 to 3992$)$ \\
\hline
\end{tabular}

* For the 43 programmes currently using some form of double reading. †Per 10000 women screened.

$\ddagger$ Additional cancers detected=(invasive cancers detected/No of women screened) $\times \%$ increase in cancers detected.

ratios for the 17 programmes currently using one view single reading. The policies are ordered in terms of increasing effectiveness. It can be seen that four policies are inefficient as they are more costly and less effective when compared with the next (more effective) option. For these 17 programmes table 4 shows the recalculated incremental cost effectiveness ratios compared with the next (more effective) alternative after the exclusion of inefficient policy options. It can be seen that one view double reading (recall if one reader suggests) is inefficient as its incremental cost effectiveness ratio is greater than the next (more effective) option. When the incremental cost effectiveness ratios were recalculated two efficient policy options resulted: one view double reading (arbitration) and two view double reading (arbitration). One view double reading (arbitration) has an incremental cost effectiveness ratio of $£ 210$. If the 17 programmes changed to this policy and subsequently introduced two views, a further five cancers per 10000 women screened could be detected efficiently with an incremental cost effectiveness ratio of $£ 7983$. Figure 1 illustrates the cost effectiveness of all policy options.

Three of the sensitivity analyses affected the policy options selected for the 17 programmes currently using one view single reading. Imputing the higher bound of the $95 \%$ confidence interval for cancers detected resulted in only one view double reading (arbitration) being efficient. Changing the configuration of arbitration reading policy changed only the basis on which one view double reading consensus became inefficient (having a higher cost effectiveness ratio than the next (more effective) policy option). The two efficient options at baseline remained efficient. Reduction of the recall rate for two views and use of alternative recall rates for the double reading policies resulted in the policy option of one view double reading (consensus) becoming efficient as well as the other two options (fig 2).

Table 5 presents the implementation costs of the policy options in England and Wales. The cost of moving all programmes to two view mammography is
$£ 2.91$ million, detecting 697 cancers; an overall cost effectiveness ratio of $£ 4176$ per additional cancer detected (assuming single reading programmes move to double reading (arbitration)). The total depends on the reading policy chosen. If two view single reading were used for programmes currently using one view single reading this would reduce the total cost slightly but detect fewer cancers. This confirms the pattern of results from tables 3 and 4 that two view single reading is not efficient and that a one view policy introducing double reading costs less and is more effective and requires fewer radiologists.

\section{Discussion}

The cost effectiveness of two view mammography at incident screens differs by reading policy. The incremental cost per additional cancer detected ranges from $£ 6589$ to $£ 6716$ for programmes currently using some form of double reading, depending on their double reading policy. For programme currently practising one view single reading at incident screens, a policy of two views and single reading was not found to be efficient. Double reading options exist that can detect more cancers at lower additional cost. The additional cost of double reading is less than that for a second view as double reading mainly requires additional reading and reporting time by the radiologists, whereas the second view requires additional films, equipment, and radiographers' and radiologists' time. From an initial set of seven alternative options, two were identified as being efficient. These were one view double reading (arbitration) and two views double reading (arbitration).

\section{Prioritising policy options}

In England and Wales the setting of national priorities will depend on whether the magnitude of the cost effectiveness ratios are deemed acceptable. ${ }^{12}$ If the ratios presented here are acceptable, two view mammography can be argued to be cost effective for all programmes in England and Wales, provided those

Table 3 Policy options ordered in terms of increasing effectiveness from baseline of one view single reading *

\begin{tabular}{|c|c|c|c|}
\hline Change from baseline to & $\begin{array}{c}\text { Additional costs } \dagger \\
\text { (£) }\end{array}$ & $\begin{array}{l}\text { Additional cancers } \\
\text { detected† }(95 \% \mathrm{CI})\end{array}$ & Incremental cost effectiveness ratio \\
\hline One view double reading (recall if one reader suggests) & 4034 & 11 (4 to 18$)$ & 366 \\
\hline Two views single reading & 35504 & 12 (4 to 23 ) & $2959 \ddagger$ \\
\hline One view double reading (consensus) & 4792 & 14 (6 to 23$)$ & $342 \ddagger$ \\
\hline Two views double reading (recall if one reader suggests) & 43572 & $16(7$ to 26$)$ & $2723 \ddagger$ \\
\hline Two views double reading (consensus) & 45089 & 19 (9 to 31$)$ & $2373 \ddagger$ \\
\hline One view double reading (arbitration) & 4413 & 21 (12 to 34$)$ & 210 \\
\hline Two views double reading (arbitration) & 44330 & 26 (14 to 31$)$ & 1705 \\
\hline
\end{tabular}


Table 4 Incremental cost effectiveness ratios compared with next (more effective) option*

\begin{tabular}{|c|c|c|c|}
\hline Change from baseline & $\begin{array}{l}\text { Additional costs } \\
(£) \dagger\end{array}$ & $\begin{array}{c}\text { Additional cancers } \\
\text { detected } \dagger\end{array}$ & $\begin{array}{l}\text { Incremental cost } \\
\text { effectiveness ratio }\end{array}$ \\
\hline \multicolumn{4}{|c|}{ Recalculated after excluding inefficient policy options identified in table 3: } \\
\hline To one view double reading (recall if one reader suggests) & 4034 & 11 & $366 \ddagger$ \\
\hline To one view double reading (arbitration) & 379 & 10 & 38 \\
\hline To two views double reading (arbitration) & 39917 & 5 & 7983 \\
\hline \multicolumn{4}{|c|}{ Recalculated after excluding policy option identified as inefficient in this table: } \\
\hline To one view double reading (arbitration) & 4413 & 21 & 210 \\
\hline To two views double reading (arbitration) & 39917 & 5 & 7983 \\
\hline
\end{tabular}

*For 17 programmes currently using one view single reading. †Per 10000 women screened.

łInefficient option as it has a higher cost effectiveness ratio than the next (more effective) option.

17 programmes currently using one view and single reading also implement double reading (arbitration). If the threshold for the acceptable cost effectiveness is below the highest ratio presented, priority should be given to implementing double reading (arbitration) in those 17 programmes currently practising one view single reading (as it has a cost effectiveness ratio of $£ 210$ per additional cancer detected). On equity grounds it can also be argued that priority should be given to the introduction of double reading in programmes currently using single reading as cancer detection rates are currently lower in these programmes.

\section{Implications of staff shortages for prioritising policy options}

Even if the cost effectiveness ratio for a policy option is deemed acceptable, it may not be feasible to implement it if there is a shortage of radiologists. For example, for the programmes currently using one view single

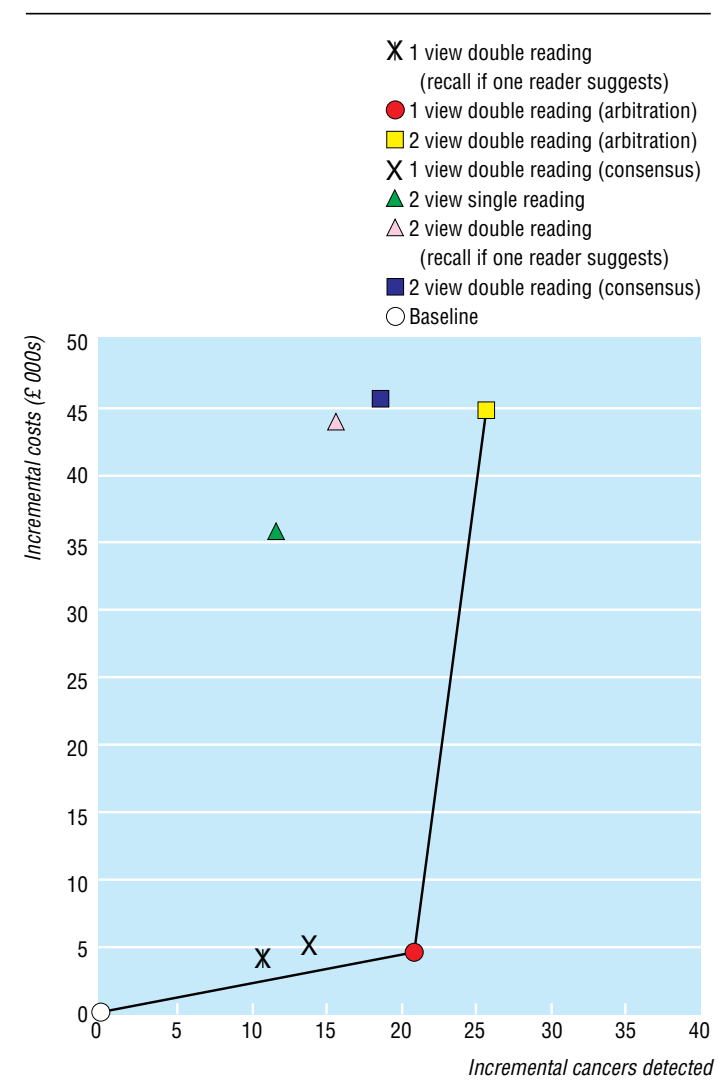

Fig 1 Cost effectiveness of policy options for 17 programmes currently performing one view single reading. Options joined by the line are efficient policy options

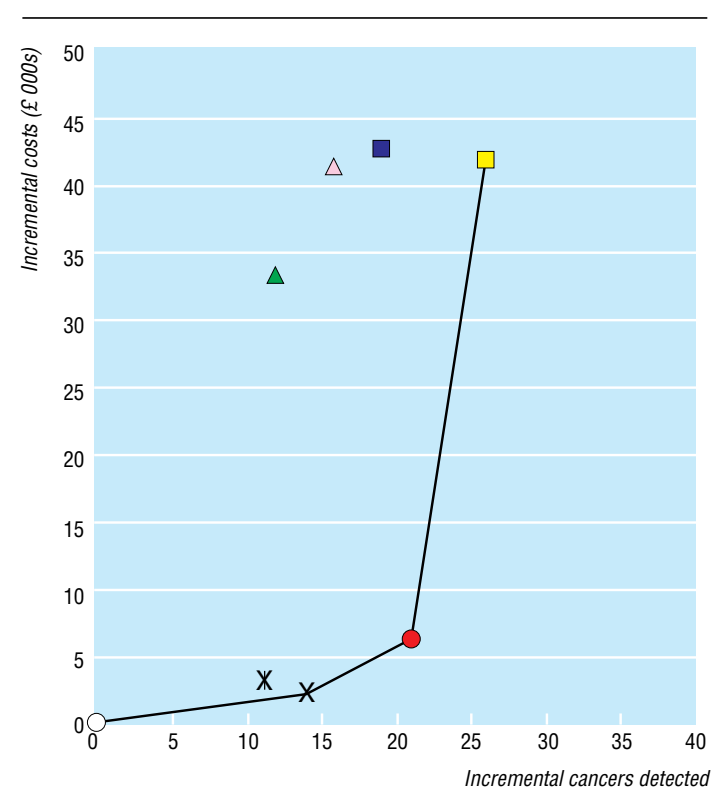

Fig 2 Sensitivity analysis on recall rates (see fig 1 for key)

reading, although two view double reading (arbitration) is the most efficient option, it is the option that requires the most additional radiology time. This is because double reading (arbitration) requires each screening programme to employ three separate radiologists. The estimates of additional staff calculated here are minimum estimates and assume divisibility across programmes so that in practice even more radiology time may be required. If there is a constraint on the number of available radiologists, then moving from one view single reading to a policy of one view double reading (consensus) or two view single reading may be preferable as these options need fewer additional whole time equivalent radiologists, even if these policies are inefficient in terms of their cost effectiveness. A constraint on available radiologists may suggest that attention should be focused instead on alternative reading modalities-such as automated or radiographer reading-but these would need to be evaluated formally in terms of their effectiveness and cost effectiveness.

\section{Recall rate}

Arguments for two view policy often rest on the presumption that the reduction in the recall rate will offset any additional resources required for the second view. There is no clear evidence that the recall rate would fall, and there is limited scope for it to fall from a baseline of $3.6 \%$. The sensitivity analysis showed that 


\begin{tabular}{|c|c|c|c|c|}
\hline Policy option & $\begin{array}{l}\text { Total cost } \\
(£)\end{array}$ & $\begin{array}{l}\text { Total cancers } \\
\text { detected }\end{array}$ & $\begin{array}{l}\text { Total WTE } \\
\text { radiologists }\end{array}$ & $\begin{array}{l}\text { Total WTE } \\
\text { radiographers }\end{array}$ \\
\hline $\begin{array}{l}\text { From baseline (one view, double reading, recall if one reader suggests) } \\
\text { to two views, double reading (recall if one reader suggests) }\end{array}$ & 769022 & 117 & 2.3 & 9.2 \\
\hline $\begin{array}{l}\text { From baseline (one view, double reading, consensus) to two views, } \\
\text { double reading (consensus) }\end{array}$ & 446298 & 66 & 1.4 & 4.2 \\
\hline $\begin{array}{l}\text { From baseline (one view, double reading, arbitration) to two views, } \\
\text { double reading (arbitration) }\end{array}$ & 257544 & 39 & 0.6 & 1.8 \\
\hline $\begin{array}{l}\text { From baseline (one view, double reading, complex) to two views, } \\
\text { double reading (complex)§ }\end{array}$ & 844177 & 127 & 2.3 & 9.2 \\
\hline $\begin{array}{l}\text { From baseline (one view, single reading) to two views, double reading } \\
\text { (arbitration)ף }\end{array}$ & 593588 & 348 & 6.8 & 5.1 \\
\hline Total implementation costs of two view policies above & 2910629 & 697 & 13.4 & 29.5 \\
\hline \multicolumn{5}{|l|}{ Alternative policy options from baseline of one view, single reading to: } \\
\hline one view, double reading (arbitration) & 59091 & 281 & 3.4 & 0 \\
\hline one view, double reading (consensus) & 64166 & 187 & 3.4 & 0 \\
\hline two views, single reading ${ }^{\star *}$ & 475406 & 161 & 1.7 & 5.1 \\
\hline
\end{tabular}

*Based on number of programmes operating a policy and number of women screened under each policy in 1996/-7 (table 1).

tAs baseline analysis assumes no change in recall rate, no savings in assessment are included.

$\ddagger$ Total costs divided by total cancers detected give cost effectiveness ratios of similar magnitude as those presented in tables 2-4. Any differences are due to

rounding of number of cancers detected in this table.

§Assumed to cost same as double reading (arbitration) and be as effective as other double reading policies.

qUsed as it is most efficient option for baseline of one view single reading.

**Inefficient option (table 3).

WTE=whole time equivalent.

\section{Key messages}

- The NHS breast screening programme is currently considering whether to introduce two view mammography at incident (subsequent) screens in England and Wales

- As individual screening programmes operate different reading policies it is important to recognise that both two views and double reading may independently increase the cancer detection rate and thus affect cost effectiveness

- A policy of two view mammography at incident screens is efficient only if programmes that use single reading also move to double reading

- Implementation of two view mammography at incident screens in programmes in England and Wales would cost £2.9 million and require 13.4 whole time equivalent radiologists

- Given the current shortage of radiologists, priority should be given to introducing double reading in the subset of programmes currently using single reading as this requires fewer additional radiologists and is more cost effective

if recall rates do fall, one view double reading (consensus) is also an efficient option.

\section{Importance of baseline}

The analysis presented here emphasises the importance of having an appropriate baseline in economic evaluations and of using incremental analysis to identify efficient options. If we had presented only the overall cost effectiveness ratio for two view mammography at incident screens in England and Wales, the prioritisation of change in policy for the programmes currently using one view and single reading would have been missed.

We thank Roger Blanks and Sue Moss of the Cancer Screening Evaluation Unit, Institute of Cancer Research, for advice and for comments on an earlier draft.
Contributors: $\mathrm{KJ}$ and $\mathrm{JB}$ designed the study, interpreted the data, and wrote the final paper. KJ collected and analysed the data and is guarantor of the work.

Funding: NHS breast screening programme.

Competing interests: None declared.

1 Forrest APM. Breast cancer screening:report to the health ministers of England, Wales and Scotland. London: HMSO, 1986.

2 NHS Executive. Quality in the national health service breast screening programme. Leeds: Quarry House, 1995.

3 Wald NJ, Murphy P, Major P, Townsend J, Frost C. UKCCCR multicentre randomised controlled trial of one and two view mammography in breast cancer screening. BMJ 1995;311:1189-96.

4 Blanks RG, Moss SM, Wallis MG. A comparison of cancer detection rates achieved by breast cancer screening programmes by number of readers, for one-view and two-view mammography: results from the UK National Health Service breast screening programme. J Med Screen 1998;5:195201

5 Johnston K, Gerard K, Morton A, Brown J. NHS costs for the breast screening frequency and age trials. Uxbridge: Brunel University, 1996. (Health Economics Research Group Discussion Paper.)

6 Brown J, Bryan S, Warren R. Mammography screening: an incremental cost effectiveness analysis of double reading versus single reading of mammograms. BMJ 1996;312: 809-12.

7 Warren RML, Duffy SW. Comparison of single reading with double reading of mammograms, and change in effectiveness with experience. Br J Radiol 1995;68:958-62.

8 Bryan S, Brown J, Warren R. Mammography screening: an incremental cost effectiveness analysis of two-view versus one-view procedures in London. J Epidemiol Community Health 1995;49:70-8.

9 Blanks RG, Day NE, Moss SM. Monitoring the performance of breast screening programmes: use of indirect standardisation in evaluating the invasive cancer detection ratio. J Med Screen 1996;32:79-81.

10 Karlsson G, Johannesson M. The decision rules of cost-effectiveness analysis. PharmacoEconomics 1996;9:113-120.

11 Briggs A, Sculpher M, Buxton M. Uncertainty in the economic evaluation of health care technologies: the role of sensitivity analysis. Health Economics 1994;3:95-104.

12 Laupacis A, Feeny D, Detsky AS, Tugwell PX. How attractive does a new technology have to be to warrant adoption and utilization? Tentative guidelines for using clinical and economic evaluations. Can Med Assoc J 1992;146:473-81.

(Accepted 19 July 1999)

\section{Endpiece}

\section{Knowledge}

Any intelligent fool can make things bigger, more complex, and more violent. It takes a touch of genius-and a lot of courage-to move in the opposite direction.

Albert Einstein 